\title{
大环多胺-咪唑鎓盐阳离子脂质的设计合成及作为基因载体的性质研究
}

\author{
付云王海蛟张骥余孝其* \\ (四川大学化学学院 绿色化学与技术教育部重点实验室 成都 610064)
}

\begin{abstract}
摘要 设计合成了 4 个含大环多胺 cyclen 亲水基团和十二酸疏水基团的两亲小分子化合物 $8 \mathbf{a} \sim 8 \mathrm{dd}$, 其结构经核磁共 振谱和高分辨质谱确证. 凝胶电泳实验结果表明, 此类化合物与 $\mathrm{Sn}$-甘油-1,2-二油酰-3-磷酰乙醇胺(DOPE)形成的阳离 子脂质体对 DNA 有很强的包裹能力. 4 种脂质体中, $8 \mathrm{a}$ 在 N/P 为 4 时可完全包裹 $\mathrm{DNA}, \mathbf{8 b} \sim \mathbf{8 d}$ 在 $\mathrm{N} / \mathrm{P}$ 为 6 时即可完全 包裹 DNA. 苂光实验也表明这四种脂质体可以有效减弱溴乙锭(EB)的苂光. 另外, 此类脂质体的粒径在 $80 \sim 120 \mathrm{~nm}$ 之 间, zeta 电位在 $+25 \sim 55 \mathrm{mV}$ 之间, 且在长达 $7 \mathrm{~d}$ 的测量时间内没有明显的变化. 此外, 我们还将该类脂质体在 A549 细 胞中进行了绿色荧光蛋白的转染实验, 8a 有中等强度的荧光表达, $8 \mathrm{~b} \sim 8 \mathrm{~d}$ 则无荧光表达. 结果表明, 此类脂质体具备了 作为非病毒基因载体的潜在性.
\end{abstract}

关键词 大环多胺; 阳离子脂质; 连接基团; 基因载体

\section{Design, Synthesis and Gene Transfection Activity of Macrocyclic Polyamine-Imidazolium Based Cationic Lipids}

\author{
$\mathrm{Fu}$, Yun Wang, Haijiao Zhang, Ji Yu, Xiaoqi* \\ (Key Laboratory of Green Chemistry and Technology-Ministry of Education, College of Chemistry, Sichuan University, \\ Chengdu 610064, China)
}

\begin{abstract}
A major challenge in gene therapy is the development of effective gene delivery vectors with low toxicity. In this study, four cyclen-based amphiphilic molecules including lauric acid moieties were designed and synthesized, and their molecular structures were confirmed by NMR and ESI-MS. These molecules have a hydrophilic cyclen headgroup and a hydrophobic long chain linking by alkyl or glycol chain, leading to different hydropohobic properties. Cationic liposomes were prepared by mixing the molecules with DOPE at various mole ratios. Agarose gel electrophoresis demonstrated that the liposomes $8 \mathbf{a}$ could condense plasmid DNA at N /P molar ratio of 4, and the ratios was 6 for $\mathbf{8 b} \sim \mathbf{8 d}$. Fluorescence quenching assay also suggested that lipids $\mathbf{8}$ have good DNA binding ability. The sizes of the formed lipoplexes were measured to be around $80 \sim 120 \mathrm{~nm}$, while zeta-potentials of the liposomes were found to be $+25 \sim 55 \mathrm{mV}$, and both of these values could remain with little change within $7 \mathrm{~d}$. Among the four lipids, 8a showed moderate in vitro gene transfection efficiency toward A549 cells, and the best transfection could be observed at N/P of 4 with $8 \mathrm{a} / \mathrm{DOPE}$ ratio of $1: 2$.

Keywords cyclen; cationic lipid; spacer; gene vector
\end{abstract}

\section{1 引言}

人类基因治疗逐渐成为现代医学发展的主要方向 之一. 基因治疗通过添加、修复或替换人体内有缺陷的 基因, 从而达到治疗疾病的目的 ${ }^{[1]}$. 基因治疗为癌症、糖 尿病、艾滋病、心血管疾病等众多疾病的治疗带来了希 望 ${ }^{[2,3]}$. 基因治疗需要将外源基因导入细胞里面并使其 高效表达, 由于体内核酸酶的存在, 在将外源基因导入 细胞的过程中, DNA 会被其所降解, 进而无法达到基因 修复的目的. 为了使外源基因能够安全地进入细胞, 一 般是将外源基因与基因载体结合, 由基因载体保护基因 免受体内体外环境所破坏. 因此, 基因载体的开发对基
因治疗的发展尤为重要.

常见的基因载体可以分为病毒载体与非病毒载体 两类 ${ }^{[4]}$. 病毒载体由于其高效的转染效率而被人们所关 注，但是病毒载体也有许多内在的缺陷，例如免疫原性， 潜在的变异性以及所运载的 DNA 尺寸过小, 这些缺陷 都阻碍了病毒载体在临床上的使用 ${ }^{[5]}$. 近年来, 非病毒 载体吸引了人们的极大关注. 与病毒载体相比, 非病毒 载体具有低毒、低免疫原性、对所运载的基因没有尺寸 上的限制及使用简单、制备方便、保存容易等优点. 常 见的非病毒载体主要有阳离子脂质体 ${ }^{[6,7]}$ 和阳离子聚合 物 ${ }^{[8,9]}$. 阳离子脂质体是最早使用的非病毒载体, 自

*E-mail: xqyu@scu.edu.cn; Fax: 0086-028-85415886

Received December 8, 2012; published February 6, 2013.

Supporting information for this article is available free of charge via the Internet at http://sioc-journal.cn.

Project supported by the National Program on Key Basic Research Project of China (973 Program, 2012CB720603, 2013CB328900) and the National Natural Science Foundation of China (No. 21232005).

项目受 973 计划(Nos. 2012CB720603, 2013CB328900)和国家自然科学基金(No. 21232005)资助. 
1987 年 Felgner 等 ${ }^{[10]}$ 首次将脂质体用作基因转染载体以 来，科学家已经针对阳离子脂质体的头部基团、连接基 团和疏水的尾部进行了许多改造, 希望通过结构活性关 系的研究，为新型阳离子脂质体的设计提供依据.

我们实验室近年来也一直从事含大环多胺的阳离

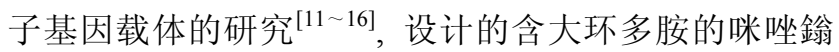
盐阳离子脂质体在体外有很好的转染效果, 尤其是在 A549 细胞中, 转染效率是商业化试剂 Lipofectamine 2000 的 5 6 倍 ${ }^{[15]}$. 也有文献报道连接基团对转染效率 有很大影响, 而且延伸的分子内空间, 高的细胞弹性和 增强的流动性有助于提高转染活性 ${ }^{[17]}$.

在实验室前期工作的基础上，我们设计合成了 4 种 阳离子脂质 $8 \mathbf{a} \sim 8 \mathrm{~d}$. 在头部 cyclen 亲水基团与疏水长链 之间插入了不同长度的亲水或疏水的连接基团, 并通过 凝胶电泳试验研究了它们与中性脂质 $\mathrm{Sn}$-甘油-1,2-二油 酰-3-磷酰乙醇胺(DOPE)形成的脂质体对 DNA 的包裹 能力, 测定了其粒径和电位以及荧光溴乙锭取代实验, 并在 A549 细胞中进行了体外转染, 发现其已具备作为 基因载体的潜在能力.

\section{2 结果与讨论}

\section{1 两亲性小分子化合物的合成}

采用 Scheme 1 所示路线合成了带有月桂酸疏水基 团的两亲性化合物 8a $\sim 8 d$, 各中间体均经 NMR 表征确 认结构, 最终化合物经过 NMR 和高分辨质谱确认结构.
首先，十二酸和不同长链的甘醇发生酯化反应得到化合 物 1, 将其羟基对甲苯磺酰化后的化合物 2 和咪唑反应， 可得到含有不同亲水性多乙二醇结构链长的中间体 $\mathbf{5 a}$ 和 5b. 对于长碳链桥联的化合物 $5 \mathrm{c}$ 和 $\mathbf{5 d}$, 则需通过月 桂酰氯和不同链长的 $\omega$-溴代脂肪醇酯化后得到的溴代 产物 4 与咪唑在 $\mathrm{KI}$ 和 $\mathrm{K}_{2} \mathrm{CO}_{3}$ 存在下反应得到. 与前期 研究 ${ }^{[15]}$ 的方法类似, 将化合物 5 与 Boc 保护的大环多胺 cyclen 中间体 $\mathbf{6}$ 在碱存在下发生咪唑的季铵化反应可得 到咪唑鎓盐 7 , 将其脱保护后, 得到目标产物三氟乙酸 盐 8. 最终产物均经核磁共振氢谱、碳谱和高分辨质谱 确认结构.

\section{2 阳离子脂质体的电泳阻滞实验}

阳离子脂质体作为基因载体，其最基本的一个目的 就是保护 DNA 免受细胞内核酸酶的降解. 因此, 在将 阳离子脂质制备成脂质体后, 进行了质粒 DNA 电泳阻 滞实验, 以找出有效保护浓缩 DNA 的 N/P 比(表示脂质 体可质子化的 $\mathrm{N}$ 原子与 DNA 磷酸基团的数量比值), 设 计阳离子脂质体/DNA 复合物的实验 $\mathrm{N} / \mathrm{P}$ 摩尔比为 0,1 , $2,4,6,8,10$. 由图 1 可知, $\mathbf{8 a}$ 在 N/P 比为 4 时就能完全 阻滞 DNA, 也就是说在 N/P 为 4 时即可完全包裹 DNA, 这与之前我们得到的脂质体类似 ${ }^{[15]}$. 而脂质体 $8 \mathbf{b} \sim 8 \mathrm{~d}$ 则在 N/P 为 6 时才能对 DNA 完全包裹. 初步表明阳离 子脂质 $8 \mathrm{a}$ 对 DNA 的包裹浓缩能力比阳离子脂质 $\mathbf{8 b} \sim$ $8 d$ 高.

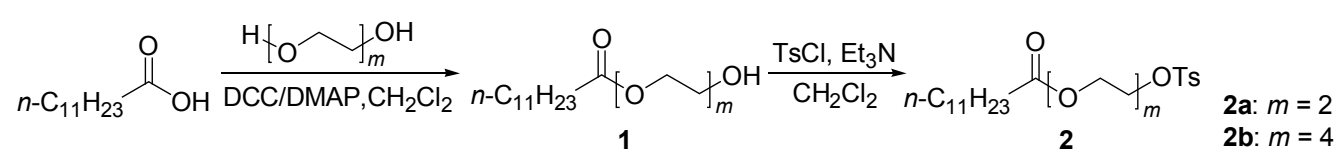
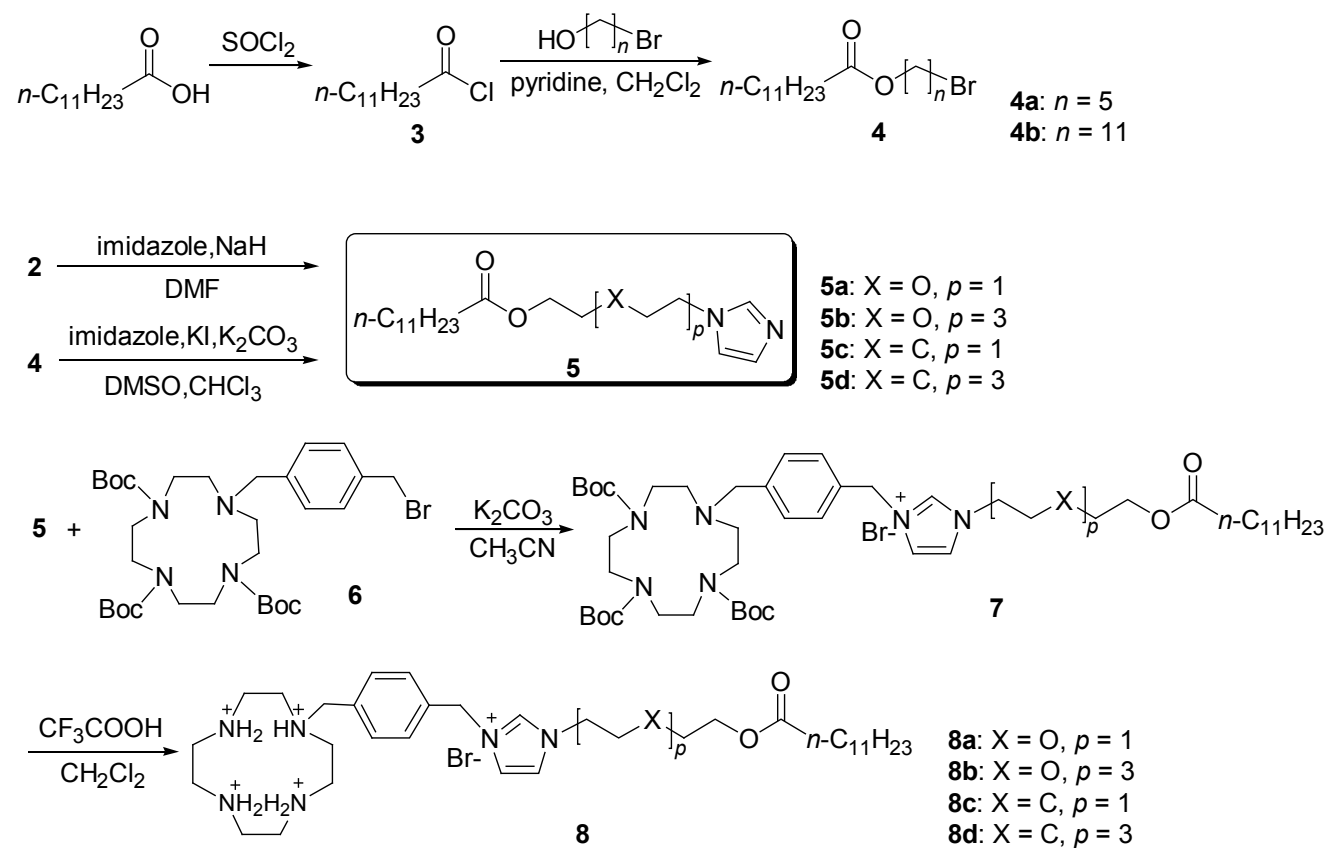

图式 1 目标化合物 8a $\sim 8 \mathrm{~d}$ 的合成路线

Scheme 1 Synthetic routes of target compounds $\mathbf{8 a} \sim \mathbf{8 d}$ 


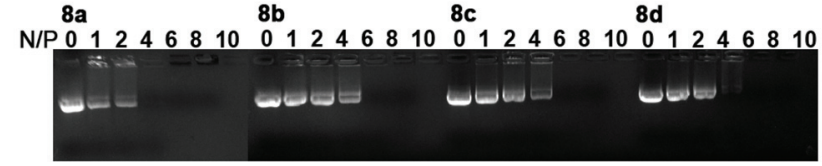

图 1 脂质体/DNA 复合物的凝胶电泳图. 8/DOPE 摩尔比为 $1: 2$ Figure 1 Electrophoretic mobility assay of liposomes/DNA complexes (lipoplexes) to determine the DNA condensation. The molar ratios of 8/DOPE were $1: 2$.

\section{3 荧光溴乙锭置换实验}

我们还利用溴乙锭荧光减弱实验对阳离子脂质体 对 DNA 的结合能力进行了表征. 溴乙锭单独使用时, 其荧光强度较弱, 但是当它与 DNA 结合之后, 荧光强 度会大大增强. 因此, 我们逐渐向溴乙锭与 DNA 的混 合液中加入阳离子脂质体, 由于阳离子脂质体会优先与 DNA 结合, 导致溴乙锭与 DNA 的分离, 进而导致荧光 强度的降低. 通过观察荧光强与所加入脂质体的关系, 可以判断出阳离子脂质体对 DNA 的包裹情况. 如图 2 所示，我们对四个阳离子脂质进行的荧光减弱实验发 现, 随着 N/P 的增加, 荧光强度迅速下降, 但是在 N/P 为 1.5 左右, 荧光强度则不再下降. $8 \mathrm{~d}$ 可使荧光降到最 低, 意味着其能置换出最多的溴乙锭.

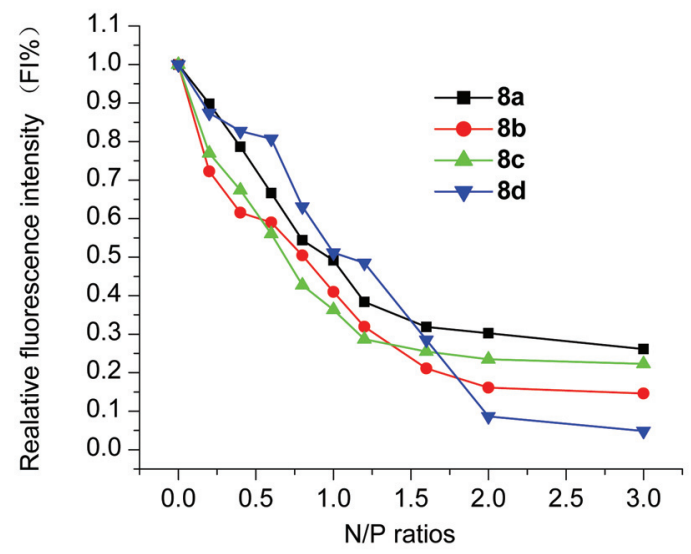

图 2 溴乙锭苂光减弱曲线

Figure 2 Change of relative fluorescence of EB bound to DNA by the addition of Liposomes prepared by $\mathbf{8}$ at different N/P ratios

\section{4 粒径及 Zeta 电位测定}

由于阳离子脂质体与 DNA 所形成的复合物要通过 内吞作用进入细胞, 所以就要求阳离子脂质体的粒径不 能过大. 而且由于细胞表面带有负电荷, 这就要求脂质 体的表面要有一定的正电荷, 这样就可以通过静电作用 相结合, 进而通过内吞作用进入细胞. 为了测定阳离子 脂质体的稳定性, 我们对未复合 DNA 的阳离子脂质体 的粒径和电位进行了一周的测定，在测定的前五天， 8a $~ 8 d$ 的粒径均比较稳定, 在 $80 \sim 120 \mathrm{~nm}$ 之间, 显示 了较好的稳定性. 对阳离子脂质体/DNA 复合物的粒径 及 zeta 电位的测定结果如图 3 所示. 我们在 PBS 溶液中
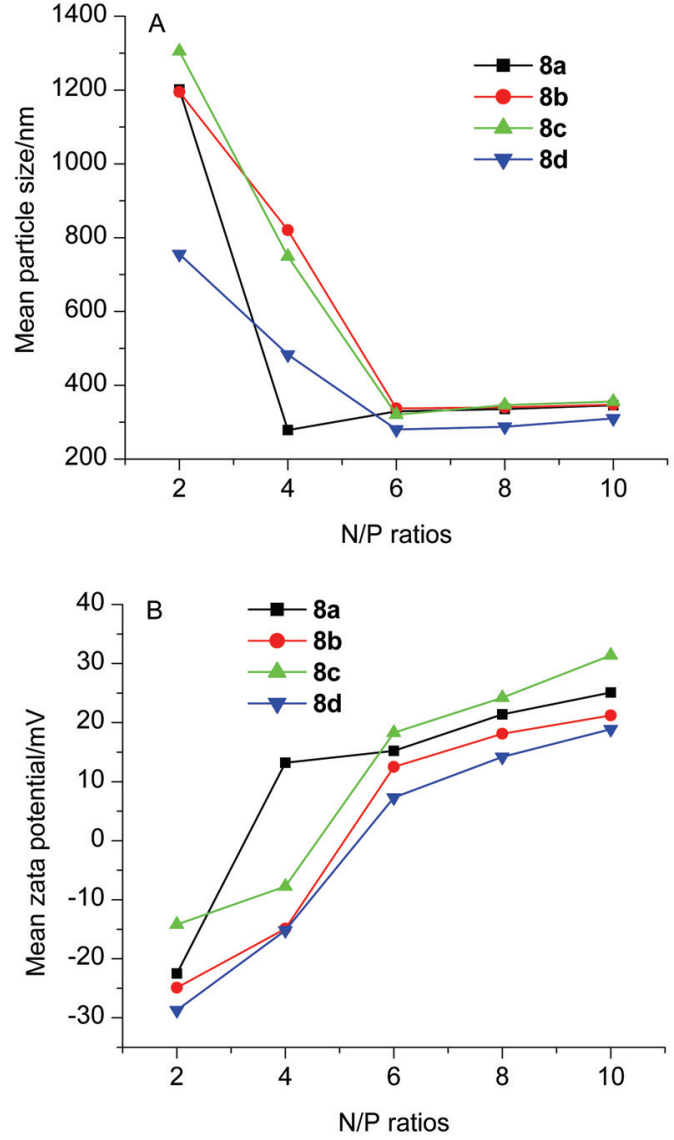

图 3 脂质体/DNA 复合物的平均粒径和表面电位

Figure 3 Mean particle sizes (A) and surface charge (B) of the 8/DNA lipoplex aggregates under various $\mathrm{N} / \mathrm{P}$ ratios

测定了阳离子脂质体/DNA 复合物在不同氮磷比 $(\mathrm{N} / \mathrm{P}=$ $2 \sim 10)$ 时的粒径和电位. 在 N/P 为 2 时, 复合物的粒径 比较大, 但是随着 $\mathrm{N} / \mathrm{P}$ 的增大, 其粒径逐渐减小, 在 $\mathrm{N} / \mathrm{P}$ 大于 4 后，其粒径稳定在 $200 \sim 300 \mathrm{~nm}$ ，显示 DNA 被完 全包裹. 其中 $8 \mathrm{a} / \mathrm{DNA}$ 复合物在 $\mathrm{N} / \mathrm{P}$ 为 4 时粒径即达到 稳定值，显示出了比 $8 \mathrm{~b} \sim 8 \mathrm{~d}$ 更好的 DNA 包裹能力，这 与凝胶电泳实验结果一致. 另外, 对于所考察的四种复 合物, 其 zeta 电位均随着 N/P 的增加而增加. N/P 比增加 到 4 以后，电位转变为正值，显示阳离子脂质体所带正 电荷已完全中和 DNA 的负电荷并占主导. 连接基团比 较长的 $8 \mathrm{~b}$ 和 $8 \mathrm{~d}$ 所形成脂质体的电位要小于连接基团较 短的 $8 \mathrm{a}$ 和 $8 \mathrm{c}$, 这应该是连接基团长度增加导致电荷密 度降低所致。

\section{5 阳离子脂质体体外细胞转染性能}

在苂光蛋白表达实验中，由于实验室前期在实验中 所采用的阳离子脂质与中性脂质 DOPE 的摩尔比例为 $1: 2$, 我们也采用相同的比例. 以 $\mathrm{pEGFP-N} 1$ 质粒为报 告基因在 A549 细胞中研究了四个阳离子脂质体在不同 氮磷比 $(\mathrm{N} / \mathrm{P}=4,6,8,10)$ 时的基因传递和表达情况. 在 所考察的四种阳离子脂质体中, 只有 $\mathbf{8 a}$ 有中等强度的 荧光表达, 8b, 8c, 和 $8 \mathrm{~d}$ 介导的荧光表达均较弱(图未列 
出). 如图 4 所示, $8 \mathbf{a}$ 的转染效果在 N/P 比为 4 时最好(图 $4 \mathrm{~A})$, 而电泳实验亦显示 $8 \mathbf{a}$ 对 DNA 的完全包裹发生在 $\mathrm{N} / \mathrm{P}$ 比为 4 时. 另外, 有文献报道 ${ }^{[18]}$, 中性脂质的用量与 种类也会对转染效率产生影响. 所以, 在 N/P 比为 4 的 情况下, 我们考察了 8a 单独使用以及不同 8a/DOPE 比 例介导的绿色菼光蛋白表达基因转染, 结果如图 5 所示. 从图中转染的结果来看, 阳离子脂质与中性脂质 DOPE 的摩尔比例对转染效果影响不大, 在 DOPE 比为 2, 3, 4 时绿色荧光蛋白的表达情况没有明显的区别, 但是有无 DOPE 却对实验有很显著的影响. 如图 5A 所示, 不加 DOPE 的转染效率要比加入 DOPE 差很多, 这表明 DOPE 的加入可以很显著的提高阳离子脂质 $8 \mathbf{a}$ 的转染 效率.

\section{3 结论}

合成了 4 个新的含大环多胺的两亲性小分子化合 物, 它们具有不同亲疏水性及不同长度的连接基团. 将 其与中性脂质 DOPE 混合制备了阳离子脂质体 $8 \mathbf{a} \sim \mathbf{8 d}$. 凝胶电泳阻滞实验结果表明, 该阳离子脂质体对 DNA 具有很强的包裹能力, 可有效保护 DNA 免受核酸酶的 降解, 其中 $8 \mathbf{a}$ 在 N/P 摩尔比为 $4: 1$ 时即可有效包裹 DNA. 另外, 对这类脂质体的粒径和 Zeta 电位进行了考 察, 所得数据满足作为基因转染材料的条件. 在 A549 细胞中的体外绿色荧光蛋白表达基因转染实验结果显 示, 含有较短亲水连接基团的化合物 8a 可介导目标基 因有效转染细胞. 以上结果显示了此类脂质体作为非病 毒基因载体的潜在性.

\section{4 实验部分}

\section{1 仪器和试剂}

仪器: Bruker AV II-400 MHz 核磁共振波谱仪, 四 甲基硅烷(TMS)为内标; Bruker Daltonics Bio TOF 型质 谱仪测定; 新芝 Scientz-IID 超声仪; Olympia 公司的 GDS 凝胶成像系统; Malvern ZEN 3600 纳米粒度及电位 分析仪; 美国 Corning 细胞培养板; 法国 JOUAN 生物安 全柜; 法国 JOUAN $\mathrm{CO}_{2}$ 培养箱; Bio-RAD model 550 酶 标仪.

试剂: 柱层析硅胶 $\mathrm{H}($ 青岛海洋化工厂，200～300 目); 琼脂糖(美国 Amor); TAE 缓冲液、PBS 缓冲液由国 产分析纯试剂配制; 染料 Goldview(上海赛百盛基因技 术有限公司); 葡萄糖溶液(太极集团西南药业股份有限 公司); 溶剂 DMSO(美国 Sigma)；1640 培养基、DMEM 培养基(美国 Gibico); pGL-3 质粒和 pEGFP-N1 质粒(美 国 Clontech); Lipofectamine 2000(美国 invitrogen); EndoFree Plasmid Kit (TIANGEN); A549 细胞株(美国 ATCC).

$$
\text { 化合物 } 3 \text { 和中间体 } 6 \text { 的合成参考文献 }{ }^{[19]} \text {. }
$$

\section{2 目标化合物的制备}

\subsection{1 化合物 $\mathbf{1}$ 的合成}

将十二酸 $(0.023 \mathrm{~mol}, 4.56 \mathrm{~g})$, 二甘醇 $(1 \mathrm{a}, 0.2 \mathrm{~mol}$, $21.2 \mathrm{~g})$ 或四甘醇 $(1 \mathrm{~b}, 0.2 \mathrm{~mol}, 38.8 \mathrm{~g})$ 和 4-二甲氨基吡啶 (DMAP, $0.003 \mathrm{~mol}, 0.366 \mathrm{~g}$ ) 溶于 $150 \mathrm{~mL}$ 二氯甲烷中, 再 将二环己基碳二亚胺(DCC, $0.02 \mathrm{~mol}, 4.12 \mathrm{~g}$ )用 $50 \mathrm{~mL}$ 二 氯甲烷溶解，在冰浴下滴加到上述溶液中，反应过夜. 将所得溶液用水洗 3 次，合并水层，用二氯甲烷反萃取
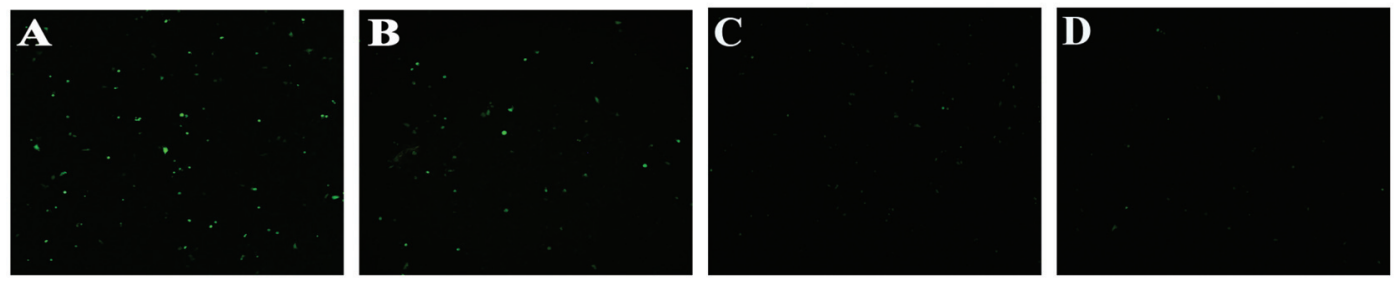

图 4 不同 $\mathrm{N} / \mathrm{P}$ 比的脂质体 $8 \mathrm{a}$ 转染绿色苂光蛋白基因到 $\mathrm{A} 549$ 细胞的苂光表达( $\mathrm{A} \sim \mathrm{D}$ 图 $\mathrm{N} / \mathrm{P}$ 比分别为 4,6,8 和 10, 8a/DOPE 摩尔比为 $1: 2$ )

Figure 4 Fluorescent microscope images of A 549 cells transfected by the lipoplexes formed from $8 a(A \sim D)$ at different N/P ratios $(A: N / P=4, B: N / P$ $=6, \mathrm{C}: \mathrm{N} / \mathrm{P}=8, \mathrm{D}: \mathrm{N} / \mathrm{P}=10), \mathbf{8 a} / \mathrm{DOPE}$ mole ratio in all experiments was $1: 2$
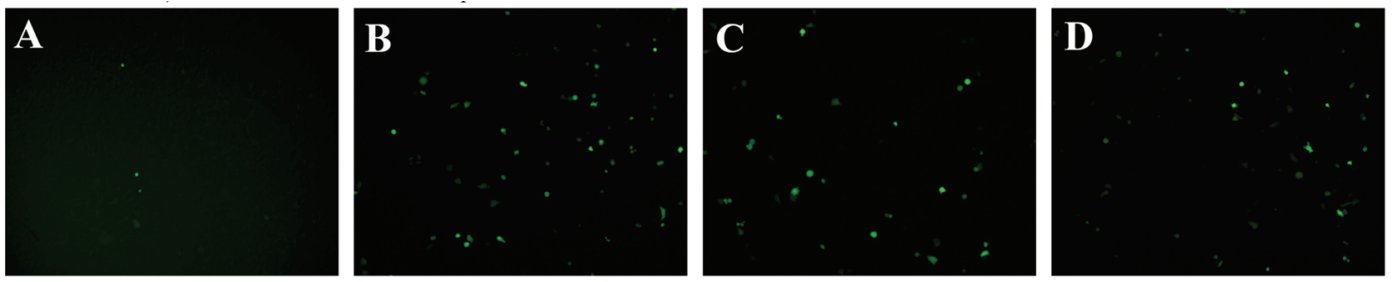

图 5 不同 8a/DOPE 摩尔比下 8a 转染绿色荧光蛋白基因到 A549 细胞的苂光表达 $(\mathrm{A} \sim \mathrm{D}$ 图 8a/DOPE 摩尔比分别为 $1: 0,1: 1,1: 2$ 和 $1: 3, \mathrm{~N} / \mathrm{P}$ 为 4)

Figure 5 Fluorescent microscope images of A 549 cells transfected by the lipoplexes formed from 8a at different 8a/DOPE mole ratios (A: $1: 0$, B: 1 : $1, \mathrm{C}: 1: 2, \mathrm{D}: 1: 3), \mathrm{N} / \mathrm{P}$ ratio in all experiments was 4 
2 次, 合并有机相, 无水硫酸钠干燥. 将有机相浓缩, 粗 产品经硅胶柱层析分离 $[V$ (石油醚 $): V($ 乙酸乙酯 $)=2$ : 1 ]得无色液体.

1a: 产率 76\%. ${ }^{1} \mathrm{H}$ NMR $\left(400 \mathrm{MHz}, \mathrm{CDCl}_{3}\right) \delta: 0.88(\mathrm{t}$, $\left.J=6.8 \mathrm{~Hz}, 3 \mathrm{H}, \mathrm{CH}_{3}\right), 1.26 \sim 1.30\left(\mathrm{~m}, 16 \mathrm{H}, \mathrm{CH}_{2}\right), 1.61 \sim$ $1.64\left(\mathrm{~m}, 2 \mathrm{H}, \mathrm{CH}_{2}\right), 2.34\left(\mathrm{t}, J=7.6 \mathrm{~Hz}, 2 \mathrm{H}, \mathrm{COCH}_{2}\right)$, $3.61 \sim 3.62\left(\mathrm{~m}, 2 \mathrm{H}, \mathrm{HOCH}_{2}\right), 3.71(\mathrm{t}, J=4.0 \mathrm{~Hz}, 2 \mathrm{H}$, $\left.\mathrm{HOCH}_{2} \mathrm{CH}_{2} \mathrm{O}\right), 3.76\left(\mathrm{t}, J=4.9 \mathrm{~Hz}, 2 \mathrm{H}, \mathrm{COCH}_{2} \mathrm{CH}_{2} \mathrm{O}\right)$, $4.25\left(\mathrm{t}, J=4.0 \mathrm{~Hz}, 2 \mathrm{H}, \mathrm{COOCH}_{2}\right) ;{ }^{13} \mathrm{C} \mathrm{NMR} \mathrm{(100} \mathrm{MHz,}$ $\left.\mathrm{CDCl}_{3}\right) \delta: 173.9,77.1,72.3,71.1,61.5,42.9,34.1,31.8$, 29.5, 29.4, 29.3, 29.2, 29.1, 24.9, 22.6, 14.1 .

1b: 产率 $80 \% .{ }^{1} \mathrm{H}$ NMR $\left(400 \mathrm{MHz}, \mathrm{CDCl}_{3}\right) \delta: 0.88$ (t, $\left.J=6.8 \mathrm{~Hz}, 3 \mathrm{H}, \mathrm{CH}_{3}\right), 1.26 \sim 1.31\left(\mathrm{~m}, 16 \mathrm{H}, \mathrm{CH}_{2}\right)$, $1.61 \sim 1.64\left(\mathrm{~m}, 2 \mathrm{H}, \mathrm{CH}_{2}\right), 2.33\left(\mathrm{t}, J=7.6 \mathrm{~Hz}, 2 \mathrm{H}, \mathrm{COCH}_{2}\right)$, $3.61 \sim 3.62(\mathrm{~m}, 2 \mathrm{H}, \mathrm{HOCH}), 3.70 \sim 3.71\left(\mathrm{~m}, 12 \mathrm{H}, \mathrm{CH}_{2}\right)$, 4.23 (t, $\left.J=4.0 \mathrm{~Hz}, 2 \mathrm{H}, \mathrm{COOCH}_{2}\right) ;{ }^{13} \mathrm{C} \mathrm{NMR}(100 \mathrm{MHz}$, $\left.\mathrm{CDCl}_{3}\right) \delta: 173.8,70.6,70.5,70.3,69.2,63.3,61.6,29.5$, $29.4,29.3,29.2,29.1,24.8,22.6,14.1$.

\section{2 .2 化合物 2 的合成}

将对甲苯磺酰氯(2.98 g, $16 \mathrm{mmol})$ 和三乙胺(1.62 g, $16 \mathrm{mmol})$ 用无水二氯甲烷溶解, 再将化合物 1 (13 mmol) 用无水二氯甲烷溶解，冰浴下将化合物 $\mathbf{1}$ 滴加到上述溶 液中, 反应过夜. 将所得溶液用水洗 3 次, 合并水层, 用 二氯甲烷反萃取 2 次, 合并有机相, 用无水硫酸钠干燥. 将有机相浓缩, 粗产品经硅胶柱层析分离 [ $V($ 石油 醚) $: V($ 乙酸乙酯 $)=1: 1]$ 得无色液体.

2a: 产率 $36 \% .{ }^{1} \mathrm{H} \mathrm{NMR}\left(400 \mathrm{MHz}, \mathrm{CDCl}_{3}\right) \delta: 0.88(\mathrm{t}$, $\left.J=6.8 \mathrm{~Hz}, 3 \mathrm{H}, \mathrm{CH}_{3}\right), 1.23 \sim 1.25\left(\mathrm{~m}, 16 \mathrm{H}, \mathrm{CH}_{2}\right), 1.57 \sim$ $1.59\left(\mathrm{~m}, 2 \mathrm{H}, \mathrm{CH}_{2}\right), 2.28\left(\mathrm{t}, J=7.6 \mathrm{~Hz}, 2 \mathrm{H}, \mathrm{COCH}_{2}\right), 2.45$ $\left(\mathrm{s}, 3 \mathrm{H}, \mathrm{ArCH}_{3}\right), 3.65 \sim 4.15\left(\mathrm{~m}, 8 \mathrm{H}, \mathrm{OCH}_{2}\right), 7.32 \sim 7.80$ $(\mathrm{m}, 4 \mathrm{H}, \mathrm{Ar}) ;{ }^{13} \mathrm{C}$ NMR $\left(100 \mathrm{MHz}, \mathrm{CDCl}_{3}\right) \delta: 173.8,144.9$, 132. 9, 129.8, 128.0, 69.1, 68.6, 63.1, 58.4, 31.9, 34.2, 29.6, 29.5, 29.3, 29.1, 24.9, 22.7, 21.6, 14.2.

2b: 产率 38\%. ${ }^{1} \mathrm{H}$ NMR (400 $\left.\mathrm{MHz}, \mathrm{CDCl}_{3}\right) \delta: 0.88$ (t, $\left.J=6.8 \mathrm{~Hz}, 3 \mathrm{H}, \mathrm{CH}_{3}\right), 1.25 \sim 1.28\left(\mathrm{~m}, 16 \mathrm{H}, \mathrm{CH}_{2}\right)$, $1.59 \sim 1.63\left(\mathrm{~m}, 2 \mathrm{H}, \mathrm{CH}_{2}\right), 2.32\left(\mathrm{t}, J=7.6 \mathrm{~Hz}, 2 \mathrm{H}, \mathrm{COCH}_{2}\right)$, $2.45\left(\mathrm{~s}, 3 \mathrm{H}, \mathrm{ArCH}_{3}\right), 3.59 \sim 3.68\left(\mathrm{~m}, 12 \mathrm{H}, \mathrm{OCH}_{2}\right), 4.16(\mathrm{t}$, $\left.J=4.4 \mathrm{~Hz}, 2 \mathrm{H}, \mathrm{SO}_{2} \mathrm{OCH}_{2}\right), 4.22(\mathrm{t}, J=6.8 \mathrm{~Hz}, 2 \mathrm{H}$, $\left.\mathrm{COOCH}_{2}\right), 7.34(\mathrm{~d}, J=7.9 \mathrm{~Hz}, 2 \mathrm{H}, \mathrm{m}-\mathrm{Ts}), 7.80$ (d, $J=7.3$ $\mathrm{Hz}, 2 \mathrm{H}, \mathrm{O}-\mathrm{Ts}) ;{ }^{13} \mathrm{C}$ NMR (100 MHz, $\left.\mathrm{CDCl}_{3}\right) \delta: 173.8$, $144.8,133.0,130.0,128.0,70.7,70.6,70.5,69.2,68.7$, $63.3,34.2,31.9,29.6,29.5,29.3,29.1,24.9,22.7,21.6$, 14.1 .

\subsection{3 化合物 4 的合成}

将化合物 3 (20 mmol) 用二氯甲烷溶解, 冰浴滴加 到溴代醇 $(20 \mathrm{mmol})$ 和三乙胺 $(4.04 \mathrm{~g}, 40 \mathrm{mmol})$ 的二氯甲 烷溶液中, 反应过夜. 将所得反应液用水洗涤 3 次, 再 用饱和碳酸氢钠溶液洗涤 3 次. 合并水层, 用二氯甲烷
反萃取 2 次，合并有机相，加入无水硫酸钠干燥. 将有 机相浓缩, 粗产品经硅胶柱层析分离(石油醚)得白色固 体.

4a: 产率 46\%. ${ }^{1} \mathrm{H} \mathrm{NMR}\left(400 \mathrm{MHz}, \mathrm{CDCl}_{3}\right) \delta: 0.86(\mathrm{t}$, $\left.J=6.8 \mathrm{~Hz}, 3 \mathrm{H}, \mathrm{CH}_{3}\right), 1.26 \sim 1.28\left(\mathrm{~m}, 28 \mathrm{H}, \mathrm{CH}_{2}\right), 1.40 \sim$ $1.42\left(\mathrm{~m}, 2 \mathrm{H}, \mathrm{BrCH}_{2} \mathrm{CH}_{2}\right), 1.57 \sim 1.66\left(\mathrm{~m}, 4 \mathrm{H}, \mathrm{CH}_{2} \mathrm{CH}_{2}-\right.$ $\mathrm{COOCH}_{2} \mathrm{CH}_{2}$ ), 2.27 (t, J=7.6 Hz, 2H, $\left.\mathrm{COCH}_{2}\right), 3.64$ (t, $\left.J=7.1 \mathrm{~Hz}, 2 \mathrm{H}, \mathrm{Br}-\mathrm{CH}_{2} \mathrm{CH}_{2}\right), 4.06$ (t, $J=4.0 \mathrm{~Hz}, 2 \mathrm{H}$, $\left.\mathrm{CH}_{2} \mathrm{CH}_{2} \mathrm{O}\right) ;{ }^{13} \mathrm{C}$ NMR $\left(100 \mathrm{MHz}, \mathrm{CDCl}_{3}\right) \delta: 174.0,64.1$ $34.2,32.1,31.8,29.5,29.3,29.2,29.1,29.0,28.3,24.9$, $22.5,22.1,13.9$.

4b: 产率 42\%. ${ }^{1} \mathrm{H}$ NMR (400 $\left.\mathrm{MHz}, \mathrm{CDCl}_{3}\right) \delta: 0.88$ (t, $\left.J=6.8 \mathrm{~Hz}, 3 \mathrm{H}, \mathrm{CH}_{3}\right), 1.26 \sim 1.28\left(\mathrm{~m}, 28 \mathrm{H}, \mathrm{CH}_{2}\right)$, $1.40 \sim 1.42\left(\mathrm{~m}, 2 \mathrm{H}, \mathrm{CH}_{2} \mathrm{CH}_{2} \mathrm{CH}_{2}\right), 1.58 \sim 1.61(\mathrm{~m}, 4 \mathrm{H}$, $\left.\mathrm{CH}_{2} \mathrm{CH}_{2} \mathrm{COOCH}_{2} \mathrm{CH}_{2}\right), 1.81 \sim 1.89\left(\mathrm{~m}, 2 \mathrm{H}, \mathrm{BrCH}_{2} \mathrm{CH}_{2}\right)$, $2.29\left(\mathrm{t}, J=7.6 \mathrm{~Hz}, 2 \mathrm{H}, \mathrm{COCH}_{2}\right), 3.40(\mathrm{t}, J=7.1 \mathrm{~Hz}, 2 \mathrm{H}$, $\left.\mathrm{BrCH}_{2} \mathrm{CH}_{2}\right), 4.05$ (t, $\left.J=4.0 \mathrm{~Hz}, 2 \mathrm{H}, \mathrm{CH}_{2} \mathrm{CH}_{2} \mathrm{O}\right) ;{ }^{13} \mathrm{C} \mathrm{NMR}$ $\left(100 \mathrm{MHz}, \mathrm{CDCl}_{3}\right) \delta: 174.0,64.3,34.4,33.9,32.8,31.9$, $29.6,29.5,29.4,29.3,29.2,28.8,28.7,28.2,25.9,25.0$, $22.7,14.1$.

4.2.4 含多乙二醇连接基团的两亲性化合物中间体 $5 \mathbf{a}$ 和 $5 b$ 的合成

将化合物 $2 \mathbf{a}$ 或 $\mathbf{2 b}(10.7 \mathrm{mmol})$ 和咪唑(7.28 g, 107 $\mathrm{mmol})$ 用 $100 \mathrm{~mL}$ DMF 溶解, 再向其中加入氢化钠 $(0.39$ $\mathrm{g}, 16.1 \mathrm{mmol}), 90{ }^{\circ} \mathrm{C}$ 加热反应 $12 \mathrm{~h}$. 将所得反应液用饱 和碳酸氢钠溶液洗涤 3 次, 合并水相, 用二氯甲烷反萃 取 2 次, 合并有机相, 加无水硫酸钠干燥. 将有机相浓 缩, 粗产品经硅胶柱层析分离 $[V$ (石油醚)： $V$ (乙酸乙酯) $=1 ： 1$ 得白色固体.

5a: 产率 $88 \% .{ }^{1} \mathrm{H}$ NMR $\left(400 \mathrm{MHz}, \mathrm{CDCl}_{3}\right) \delta: 0.87(\mathrm{t}$, $\left.J=6.8 \mathrm{~Hz}, 3 \mathrm{H}, \mathrm{CH}_{3}\right), 1.26 \sim 1.29\left(\mathrm{~m}, 16 \mathrm{H}, \mathrm{CH}_{2}\right), 1.60 \sim$ $1.63\left(\mathrm{~m}, 2 \mathrm{H}, \mathrm{CH}_{2}\right), 2.28\left(\mathrm{t}, J=7.6 \mathrm{~Hz}, 2 \mathrm{H}, \mathrm{COCH}_{2}\right)$, $3.62 \sim 3.71\left(\mathrm{~m}, 4 \mathrm{H}, \mathrm{OCH}_{2}\right), 4.12(\mathrm{t}, J=6.8 \mathrm{~Hz}, 2 \mathrm{H}$, $\left.\mathrm{COOCH}_{2}\right), 4.17\left(\mathrm{t}, J=6.7 \mathrm{~Hz}, 2 \mathrm{H}\right.$, Imidazole- $\left.\mathrm{CH}_{2}\right), 6.99$ (s, 1H, Imidazole-H), 7.04 (s, 1H, Imidazole-H), 7.52 (s, $1 \mathrm{H}$, Imidazole-H); ${ }^{13} \mathrm{C}$ NMR (100 MHz, $\left.\mathrm{CDCl}_{3}\right) \delta: 173.8$, 137.5, 129.3, 119.4, 70.4, 69.3, 62.9, 47.0, 34.2, 31.9, 29.6, 29.5, 29.3, 29.1, 24.9, 22.7, 14.1.

5b: 产率 74\%. ${ }^{1} \mathrm{H}$ NMR (400 $\left.\mathrm{MHz}, \mathrm{CDCl}_{3}\right), \delta: 0.83$ $\left(\mathrm{t}, J=6.8 \mathrm{~Hz}, 3 \mathrm{H}, \mathrm{CH}_{3}\right), 1.21 \sim 1.23\left(\mathrm{~m}, 16 \mathrm{H}, \mathrm{CH}_{2}\right)$, $1.53 \sim 1.56\left(\mathrm{~m}, 2 \mathrm{H}, \mathrm{CH}_{2}\right), 2.32\left(\mathrm{t}, J=7.6 \mathrm{~Hz}, 2 \mathrm{H}, \mathrm{COCH}_{2}\right)$, $3.57 \sim 3.69\left(\mathrm{~m}, 12 \mathrm{H}, \mathrm{OCH}_{2}\right), 4.06(\mathrm{t}, J=6.8 \mathrm{~Hz}, 2 \mathrm{H}$, $\left.\mathrm{COOCH}_{2}\right), 4.17\left(\mathrm{t}, J=6.7 \mathrm{~Hz}, 2 \mathrm{H}\right.$, Imidazole- $\left.\mathrm{CH}_{2}\right), 6.99$ (d, $J=6.7 \mathrm{~Hz}, 2 \mathrm{H}$, Imidazole-H), 7.52 (s, 1H, Imidazole-H); ${ }^{13} \mathrm{C}$ NMR $\left(100 \mathrm{MHz}, \mathrm{CDCl}_{3}\right) \delta: 173.9,72.4,71.1$, $69.1,63.2,61.5,42.9,34.1,31.8,29.5,29.4,29.3,29.2$, $29.1,24.9,22.6,14.1$. 
4.2.5 含长碳链连接基团的两亲性化合物中间体 $5 \mathrm{c}$ 和 $5 d$ 的合成

取 $100 \mathrm{~mL}$ 圆底烧瓶, 分别向其中加入化合物 $\mathbf{4 a}$ 或 4b $(8 \mathrm{mmol})$, 咪唑 $(80 \mathrm{mmol})$, 碘化钾 $(0.1 \mathrm{~g})$ 和碳酸钠 $(1.2 \mathrm{~g})$. 再加入 $20 \mathrm{~mL}$ DMSO, $30 \mathrm{~mL}$ 无水氯仿, $90{ }^{\circ} \mathrm{C}$ 反 应 $8 \mathrm{~h}$. 抽滤去除固体杂质, 将所得滤液用饱和碳酸氢 钠溶液洗涤 3 次, 饱和食盐水洗涤 3 次, 合并水相, 用二 氯甲烷反萃取 2 次, 合并有机相, 用无水硫酸钠干燥. 将有机相浓缩, 粗产品经硅胶柱层析分离 $[V$ (石油醚) : $V($ 乙酸乙酯 $)=2: 1]$ 得白色固体.

5c: 产率 55\%. ${ }^{1} \mathrm{H}$ NMR $\left(400 \mathrm{MHz}, \mathrm{CDCl}_{3}\right) \delta: 0.88(\mathrm{t}$, $\left.J=6.8 \mathrm{~Hz}, 3 \mathrm{H}, \mathrm{CH}_{3}\right), 1.26 \sim 1.28\left(\mathrm{~m}, 18 \mathrm{H}, \mathrm{CH}_{2}\right), 1.62 \sim$ $1.80\left(\mathrm{~m}, 6 \mathrm{H}, \mathrm{CH}_{2}\right), 2.31\left(\mathrm{t}, J=7.6 \mathrm{~Hz}, 2 \mathrm{H}, \mathrm{COCH}_{2}\right), 3.94$ (t, $\left.J=6.8 \mathrm{~Hz}, 2 \mathrm{H}, \mathrm{COOCH}_{2}\right), 4.05$ (t, $J=6.7 \mathrm{~Hz}, 2 \mathrm{H}$, imidazole- $\left.\mathrm{CH}_{2}\right), 6.90(\mathrm{~s}, 1 \mathrm{H}$, imidazole-H), 7.04 (s, $1 \mathrm{H}$, imidazole-H), 7.46 (s, 1H, imidazole-H); ${ }^{13} \mathrm{C}$ NMR (100 MHz, $\left.\mathrm{CDCl}_{3}\right) \delta: 173.9,137.0,129.4,118.7,63.7,46.8,34.3$, $31.9,30.7,29.6,29.4,29.3,29.2,29.1,28.1,24.9,23.0$, 22.6, 14.1 .

5d: 产率 51\%. ${ }^{1} \mathrm{H}$ NMR (400 $\left.\mathrm{MHz}, \mathrm{CDCl}_{3}\right) \delta: 0.88$ (t, $\left.J=6.8 \mathrm{~Hz}, 3 \mathrm{H}, \mathrm{CH}_{3}\right), 1.21 \sim 1.26\left(\mathrm{~m}, 30 \mathrm{H}, \mathrm{CH}_{2}\right)$, $1.59 \sim 1.77\left(\mathrm{~m}, 6 \mathrm{H}, \mathrm{CH}_{2}\right), 2.27\left(\mathrm{t}, J=7.6 \mathrm{~Hz}, 2 \mathrm{H}, \mathrm{COCH}_{2}\right)$, 3.92 (t, $J=6.8 \mathrm{~Hz}, 2 \mathrm{H}, \mathrm{COOCH}_{2}$ ), 4.05 (t, $J=6.7 \mathrm{~Hz}, 2 \mathrm{H}$, imidazole- $\left.\mathrm{CH}_{2}\right), 6.90(\mathrm{~s}, 1 \mathrm{H}$, imidazole-H), $7.04(\mathrm{~s}, 1 \mathrm{H}$, imidazole-H), 7.45 (s, 1H, imidazole-H); ${ }^{13} \mathrm{C}$ NMR (100 $\left.\mathrm{MHz}, \mathrm{CDCl}_{3}\right) \delta: 173.8,136.9,129.1,118.6,64.2,46.9$, $34.3,31.8,30.9,29.5,29.3,29.2,29.1,29.0,28.9,28.5$, $26.4,25.8,24.9,22.5,14.0$.

4.2 .6 化合物 7 的合成

将中间体 5 (6 mmol) 与化合物 6 (9 mmol) 溶解于 30 $\mathrm{mL}$ 无水乙腈中, 回流反应, 用薄层层析监测反应的进 行情况, 反应 48 96 h 后, 旋蒸除去乙腈, 柱层析分离 $[V($ 二氯甲烷 $): V($ 甲醇 $)=20 ： 1$ 得到泡沫状黄色油状物 质 7 .

7a: 产率 40\%. ${ }^{1} \mathrm{H} \mathrm{NMR}\left(400 \mathrm{MHz}, \mathrm{CDCl}_{3}\right) \delta: 0.87(\mathrm{t}$, $\left.J=6.8 \mathrm{~Hz}, 3 \mathrm{H}, \mathrm{CH}_{3}\right), 1.11 \sim 1.33\left(\mathrm{~m}, 16 \mathrm{H}, \mathrm{CH}_{2}\right), 1.43 \sim$ $1.51\left(\mathrm{~m}, \quad 27 \mathrm{H}, \quad(\mathrm{N}-\mathrm{Boc})_{3}\right), 1.62 \sim 1.64(\mathrm{~m}, \quad 2 \mathrm{H}$, $\left.\mathrm{COOCH}_{2} \mathrm{CH}_{2}\right), 2.33\left(\mathrm{t}, J=6.8 \mathrm{~Hz}, 2 \mathrm{H}, \mathrm{COOCH}_{2} \mathrm{CH}_{2}\right)$, $2.62 \sim 2.64$ (m, 4H, cyclen-H), 3.30 3.69 (m, 12H, cyclen-H), 3.76 (s, 2H, ArCH -cyclen), 3.77 3.81 (m, 4H, $\left.\mathrm{OCH}_{2} \mathrm{CH}_{2}\right), 4.51\left(\mathrm{t}, J=7.6 \mathrm{~Hz}, 2 \mathrm{H}, \mathrm{CH}_{2} \mathrm{OCO}\right), 4.76(\mathrm{t}, J=$ $\left.7.6 \mathrm{~Hz}, 2 \mathrm{H}, \mathrm{NCH}_{2} \mathrm{CH}_{2} \mathrm{OCO}\right), 7.31$ (d, $J=9.2 \mathrm{~Hz}, 2 \mathrm{H}$, Ar-H), 7.41 (d, $J=11.9 \mathrm{~Hz}, 1 \mathrm{H}$, imidazole-H), 7.48 (d, $J=$ $9.2 \mathrm{~Hz}, 2 \mathrm{H}, \mathrm{Ar}-\mathrm{H}), 7.70$ (s, 1H, imidazole-H), 10.44 (s, 1H, imidazole-H); ${ }^{13} \mathrm{C}$ NMR $\left(100 \mathrm{MHz}, \mathrm{CDCl}_{3}\right) \delta$ : 173.7, $137.4,131.5,130.9,130.6,129.7,128.9,123.5,120.8$, $77.3,77.1,76.8,69.4,68.0,68.8,68.1,65.8,62.8,58.3$, $53.2,50.0,34.2,31.9,29.6,29.5,29.3,29.1,28.7,28.5$,
28.0, 24.9, 22.7, 14.1 .

7b: 产率 $62 \% .{ }^{1} \mathrm{H}$ NMR $\left(400 \mathrm{MHz}, \mathrm{CDCl}_{3}\right) \delta: 0.86$ $\left(\mathrm{t}, J=6.8 \mathrm{~Hz}, 3 \mathrm{H}, \mathrm{CH}_{3}\right), 1.22 \sim 1.33\left(\mathrm{~m}, 16 \mathrm{H}, \mathrm{CH}_{2}\right)$, $1.42 \sim 1.58\left(\mathrm{~m}, 27 \mathrm{H},(\mathrm{N}-\mathrm{Boc})_{3}\right), 1.70 \sim 1.72(\mathrm{~m}, 2 \mathrm{H}$, $\left.\mathrm{COOCH}_{2} \mathrm{CH}_{2}\right), 2.25\left(\mathrm{t}, J=6.8 \mathrm{~Hz}, 2 \mathrm{H}, \mathrm{COOCH}_{2} \mathrm{CH}_{2}\right)$, $2.58 \sim 2.64(\mathrm{~m}, 4 \mathrm{H}$, cyclen-H), 3.33 $3.72(\mathrm{~m}, 12 \mathrm{H}$, cyclen-H), 3.76 (s, 2H, $\mathrm{ArCH}_{2}$-cyclen), $3.8(\mathrm{~s}, 12 \mathrm{H}$, $\left.\mathrm{OCH}_{2} \mathrm{CH}_{2}\right), 4.51\left(\mathrm{t}, J=6.8 \mathrm{~Hz}, 2 \mathrm{H}, \mathrm{CH}_{2} \mathrm{OCO}\right), 4.78$ (t, $J=$ $\left.7.6 \mathrm{~Hz}, 2 \mathrm{H}, \mathrm{NCH}_{2} \mathrm{CH}_{2} \mathrm{OCO}\right), 7.35(\mathrm{~d}, J=9.2 \mathrm{~Hz}, 2 \mathrm{H}$, Ar-H), $7.41 \sim 7.77$ (m, 3H, imidazole-H); ${ }^{13} \mathrm{C}$ NMR $(100$ $\left.\mathrm{MHz}, \mathrm{CDCl}_{3}\right) \delta: 172.8,155.1,154.8,154.4,136.0,131.0$, $130.2,129.5,127.9,122.7,120.3,76.6,76.3,76.0,69.5$, $69.4,69.3,68.1,67.9,62.2,56.9,54.9,52.6,52.0,48.8$, $28.7,28.6,28.4,28.3,28.1,27.7,27.5,27.0,23.9,21.7$, 13.1 .

7c: 产率 57\%. ${ }^{1} \mathrm{H}$ NMR $\left(400 \mathrm{MHz}, \mathrm{CDCl}_{3}\right) \delta: 0.90(\mathrm{t}$, $\left.J=6.8 \mathrm{~Hz}, 3 \mathrm{H}, \mathrm{CH}_{3}\right), 1.22 \sim 1.26\left(\mathrm{~m}, 18 \mathrm{H}, \mathrm{CH}_{2}\right), 1.45 \sim$ $1.48\left(\mathrm{~m}, 27 \mathrm{H},(\mathrm{N}-\mathrm{Boc})_{3}\right), 2.02 \sim 2.27\left(\mathrm{~m}, 6 \mathrm{H}, \mathrm{CH}_{2}\right), 2.30$ $\left(\mathrm{t}, J=6.8 \mathrm{~Hz}, 2 \mathrm{H}, \mathrm{CH}_{2} \mathrm{COOCH}_{2}\right), 2.62 \sim 2.64$ (m, 4H, cyclen-H), $3.06 \sim 3.10\left(\mathrm{~m}, 4 \mathrm{H}, \mathrm{OCH}_{2} \mathrm{CH}_{2}\right), 3.35 \sim 3.56(\mathrm{~m}$, $12 \mathrm{H}$, cyclen-H), $4.34\left(\mathrm{t}, J=6.7 \mathrm{~Hz}, 2 \mathrm{H}, \mathrm{CH}_{2} \mathrm{OCO}\right), 4.71$ (s, 2H, ArCH- -Cyclen), 5.59 (t, $J=7.6 \mathrm{~Hz}, 2 \mathrm{H}, \operatorname{ArCH}_{2} \mathrm{~N}$ $(\mathrm{CH})(\mathrm{CH})), 7.14 \sim 7.22(\mathrm{~m}, 4 \mathrm{H}, \mathrm{Ar}-\mathrm{H}), 7.34$ (s, 1H, imidazole-H), 10.80 (s, 1H, imidazole-H); ${ }^{13} \mathrm{C}$ NMR (100 $\left.\mathrm{MHz}, \mathrm{CDCl}_{3}\right) \delta: 173.8,137.8,131.5,131.3,129.0,121.6$, $121.4,77.3,77.0,76.7,63.4,58.4,56.3,53.3,50.0,47.9$, $47.5,34.3,31.9,29.8,29.6,29.5,29.3,29.2,28.7,28.5$, 28.0, 25.0, 22.8, 22.7, 18.4, 14.1.

7d: 产率 44\%. ${ }^{1} \mathrm{H}$ NMR (400 MHz, $\left.\mathrm{CDCl}_{3}\right) \delta: 0.87$ (t, $\left.J=6.8 \mathrm{~Hz}, 3 \mathrm{H}, \mathrm{CH}_{3}\right), 1.26 \sim 1.28\left(\mathrm{~m}, 30 \mathrm{H}, \mathrm{CH}_{2}\right), 1.33$ $\left(\mathrm{m}, 27 \mathrm{H},(\mathrm{N}-\mathrm{Boc})_{3}\right), 1.58 \sim 1.62\left(\mathrm{~m}, 2 \mathrm{H}, \mathrm{COOCH}_{2} \mathrm{CH}_{2}\right)$, $2.33\left(\mathrm{t}, J=6.8 \mathrm{~Hz}, 2 \mathrm{H}, \mathrm{COOCH}_{2} \mathrm{CH}_{2}\right), 2.62 \sim 2.68(\mathrm{~m}, 4 \mathrm{H}$, cyclen-H), $3.30 \sim 3.49(\mathrm{~m}, 12 \mathrm{H}$, cyclen-H), $3.54 \sim 3.60(\mathrm{~m}$, $4 \mathrm{H}, \mathrm{OCH}_{2} \mathrm{CH}_{2}$ ), 3.74 (s, 2H, $\mathrm{ArCH}_{2}$-Cyclen), 4.05 (t, $J=$ $\left.7.6 \mathrm{~Hz}, 2 \mathrm{H}, \mathrm{CH}_{2} \mathrm{OCO}\right), 4.30$ (t, $J=7.6 \mathrm{~Hz}, 2 \mathrm{H}$, $\left.\mathrm{NCH}_{2} \mathrm{CH}_{2} \mathrm{OCO}\right), 7.18 \sim 7.30(\mathrm{~m}, 4 \mathrm{H}, \mathrm{Ar}-\mathrm{H}), 7.42 \sim 10.79$ (m, 3H, imidazole-H); ${ }^{13} \mathrm{C}$ NMR $\left(100 \mathrm{MHz}, \mathrm{CDCl}_{3}\right) \delta$ : 173.0, 136.1, 130.1, 129.5, 128.9, 128.0, 120.9, 78.5, 76.4, $76.2,75.9,63.3,57.1,52.0,49.2,33.4,30.9,29.3,28.6$, $28.4,28.3,28.2,28.1,28.0,27.7,27.6,27.5,25.3,24.9$, 24.0, 21.7, 13.1,

\subsection{7目标化合物 8 的合成}

将 $2.5 \mathrm{mmol}$ 前体化合物 7 溶解在 $10 \mathrm{~mL}$ 无水二氯 甲烷溶液中，在冰水浴冷却条件下 $5 \mathrm{~mL}$ 三氟醋酸溶解 于 $5 \mathrm{~mL}$ 无水二氯甲烷的溶液, 滴加完毕后, 撤去冰水 浴室温下反应 $12 \mathrm{~h}$, 旋蒸除去二氯甲烷后干燥得到浅黄 色液体产物.

8a: 产率 $86 \% .{ }^{1} \mathrm{H}$ NMR (DMSO- $\left.d_{6}, 400 \mathrm{MHz}\right) \delta$ : 
$0.85\left(\mathrm{t}, J=6.8 \mathrm{~Hz}, 3 \mathrm{H}, \mathrm{CH}_{3}\right), 1.23 \sim 1.49\left(\mathrm{~m}, 16 \mathrm{H}, \mathrm{CH}_{2}\right)$, $1.35 \sim 1.41\left(\mathrm{~m}, 2 \mathrm{H}, \mathrm{COOCH}_{2} \mathrm{CH}_{2}\right), 2.25(\mathrm{t}, J=6.8 \mathrm{~Hz}, 2 \mathrm{H}$, $\left.\mathrm{OCOCH}_{2} \mathrm{CH}_{2}\right), 2.48 \sim 2.52\left(\mathrm{~m}, 4 \mathrm{H}, \mathrm{PhN}\left(\mathrm{CH}_{2}\right)_{2}\right), 2.78 \sim$ $2.82\left(\mathrm{~m}, 4 \mathrm{H}, \mathrm{N}\left(\mathrm{CH}_{2} \mathrm{CH}_{2}\right)_{2}\right), 2.99 \sim 3.18\left(\mathrm{~m}, 8 \mathrm{H}, \mathrm{N}\left(\mathrm{CH}_{2}-\right.\right.$ $\left.\left.\mathrm{CH}_{2}\right)_{2}\right), 3.62\left(\mathrm{~s}, 2 \mathrm{H}, \mathrm{ArCH}_{2} \mathrm{~N}\right), 3.62 \sim 3.74\left(\mathrm{~m}, 4 \mathrm{H}, \mathrm{OCH}_{2}-\right.$ $\mathrm{CH}_{2}$ ), 4.10 (t, $\left.J=7.6 \mathrm{~Hz}, 2 \mathrm{H}, \mathrm{CH}_{2} \mathrm{OCO}\right), 4.38$ (t, $J=7.6$ $\left.\mathrm{Hz}, 2 \mathrm{H}, \mathrm{NCH}_{2} \mathrm{CH}_{2} \mathrm{O}\right), 5.44\left(\mathrm{~s}, 2 \mathrm{H}, \operatorname{ArCH}_{2} \mathrm{~N}(\mathrm{CH})(\mathrm{CH})\right)$, $7.30 \sim 7.36\left(\mathrm{~m}, 4 \mathrm{H}, \mathrm{CH}_{2} \mathbf{A r C H}_{2}\right), 7.77$ (s, 1H, imidazole-H), 9.36 (s, $1 \mathrm{H}$, imidazole-H); ${ }^{13} \mathrm{C}$ NMR (100 MHz, DMSO- $\left.d_{6}\right) \delta: 173.0,131.1,128.8,123.7,122.7,68.6,68.4$, $63.3,49.3,47.4,44.9,42.5,40.6,40.4,40.2,40.0,39.7$, $39.5,39.3,33.8,31.7,29.4,29.2,29.3,28.9,24.9,22.6$, 14.4. HRMS $\mathrm{C}_{48} \mathrm{H}_{73} \mathrm{~N}_{6} \mathrm{O}_{4}$ calcd 613.4805; found 613.4760.

8b: 产率 $77 \% .{ }^{1} \mathrm{H}$ NMR (DMSO- $\left.d_{6}, 400 \mathrm{MHz}\right) \delta: 0.85$ $\left(\mathrm{t}, J=6.8 \mathrm{~Hz}, 3 \mathrm{H}, \mathrm{CH}_{3}\right), 1.23 \sim 1.49\left(\mathrm{~m}, 16 \mathrm{H}, \mathrm{CH}_{2}\right)$, $1.36 \sim 1.40\left(\mathrm{~m}, 2 \mathrm{H}, \mathrm{COOCH}_{2} \mathrm{CH}_{2}\right), 2.25(\mathrm{t}, J=6.8 \mathrm{~Hz}, 2 \mathrm{H}$, $\left.\mathrm{OCOCH}_{2} \mathrm{CH}_{2}\right), 2.48 \sim 2.52\left(\mathrm{~m}, 4 \mathrm{H}, \mathrm{PHN}\left(\mathrm{CH}_{2}\right)_{2}\right), 2.78 \sim$ $2.82\left(\mathrm{~m}, 4 \mathrm{H}, \mathrm{N}\left(\mathrm{CH}_{2} \mathrm{CH}_{2}\right)_{2}\right), 2.99 \sim 3.18(\mathrm{~m}, 8 \mathrm{H}$, $\left.\mathrm{N}\left(\mathrm{CH}_{2} \mathrm{CH}_{2}\right)_{2}\right), 3.62\left(\mathrm{~s}, 2 \mathrm{H}, \operatorname{ArCH}_{2} \mathrm{~N}\left(\mathrm{CH}_{2} \mathrm{CH}_{2}\right)_{2}\right), 3.74 \sim$ $3.80\left(\mathrm{~m}, 4 \mathrm{H}, \mathrm{OCH}_{2} \mathrm{CH}_{2}\right), 4.10(\mathrm{t}, J=7.6 \mathrm{~Hz}, 2 \mathrm{H}$, $\mathrm{CH}_{2} \mathrm{OCO}$ ), 4.38 (t, J=7.6 Hz, 2H, $\mathrm{NCH}_{2} \mathrm{CH}_{2} \mathrm{O}$ ), 5.44 (s, $\left.2 \mathrm{H}, \operatorname{ArCH}_{2} \mathrm{~N}(\mathrm{CH})(\mathrm{CH})\right), 7.30 \sim 7.36\left(\mathrm{~m}, 4 \mathrm{H}, \mathrm{CH}_{2} \mathbf{A r C H}_{2}\right)$, 7.77 (s, $1 \mathrm{H}$, imidazole-H), $9.36(\mathrm{~s}, 1 \mathrm{H}$, imidazole- $\mathrm{H}) ;{ }^{13} \mathrm{C}$ NMR (100 MHz, DMSO- $\left.d_{6}\right) \delta: 173.0,136.4,135.6,133.9$, $130.6,129.7,128.3,123.2,122.2,69.6,69.5,69.4,68.2$, $68.0,63.0,55.0,51.2,48.9,46.9,44.6,41.9,39.9,39.7$, 39.4, 39.2, 39.0, 38.8, 38.6, 33.3, 31.2, 28.9, 28.8, 28.6, 28.3, 24.4, 22.0, 13.9. HRMS $\mathrm{C}_{39} \mathrm{H}_{69} \mathrm{~N}_{6} \mathrm{O}_{5}$ calcd 701.5329; found 701.5247 .

8c: 产率 $82 \% .{ }^{1} \mathrm{H}$ NMR (DMSO- $\left.d_{6}, 400 \mathrm{MHz}\right) \delta$ : $0.85\left(\mathrm{t}, J=6.8 \mathrm{~Hz}, 3 \mathrm{H}, \mathrm{CH}_{3}\right), 1.05 \sim 1.28(\mathrm{~m}, 16 \mathrm{H}$, $\left.\left(\mathrm{CH}_{2}\right)_{8} \mathrm{CH}_{3}\right), 1.47 \sim 1.82\left(\mathrm{~m}, 6 \mathrm{H}, \mathrm{CH}_{2}\right), 2.25(\mathrm{t}, J=6.8 \mathrm{~Hz}$, $\left.2 \mathrm{H}, \mathrm{OCOCH}_{2} \mathrm{CH}_{2}\right), 2.66 \sim 2.73\left(\mathrm{~m}, 4 \mathrm{H}, \mathrm{PhN}\left(\mathrm{CH}_{2}\right)_{2}\right)$, $2.81 \sim 2.84\left(\mathrm{~m}, 4 \mathrm{H}, \mathrm{N}\left(\mathrm{CH}_{2} \mathrm{CH}_{2}\right)_{2}\right), 3.04 \sim 3.12(\mathrm{~m}, 8 \mathrm{H}$, $\left.\mathrm{N}\left(\mathrm{CH}_{2} \mathrm{CH}_{2}\right)_{2}\right), 3.74$ (s, 2H, $\left.\operatorname{ArCH} \mathrm{H}_{2}\left(\mathrm{CH}_{2} \mathrm{CH}_{2}\right)_{2}\right), 3.99$ (t, $\left.J=7.6 \mathrm{~Hz}, 2 \mathrm{H}, \mathrm{CH}_{2} \mathrm{OCO}\right), 4.18(\mathrm{t}, J=7.9 \mathrm{~Hz}, 2 \mathrm{H}$, $\left.\mathrm{NCH}_{2} \mathrm{CH}_{2}\right), 5.42\left(\mathrm{~s}, 2 \mathrm{H}, \operatorname{ArCH}{ }_{2} \mathrm{~N}(\mathrm{CH})(\mathrm{CH})\right), 7.39 \sim 7.40$ (m, 4H, $\left.\mathrm{CH}_{2} \mathrm{ArCH}_{2}\right), 7.81$ (s, 1H, imidazole-H), 9.34 (s, $1 \mathrm{H}$, imidazole-H); ${ }^{13} \mathrm{C}$ NMR (100 MHz, DMSO- $\left.d_{6}\right) \delta$ : $172.9,136.1,135.8,133.9,130.6,128.3,122.8,122.5$, $118.6,115.5,63.3,56.0,54.9,51.6,48.7,47.0,44.6,42.0$, $41.9,40.0,39.8,39.6,39.4,39.2,39.0,38.8,33.4,31.2$, 28.9, 28.8, 28.7, 28.6, 28.4, 27.4, 24.4, 22.1, 13.9. HRMS $\left(\mathrm{C}_{36} \mathrm{H}_{63} \mathrm{~N}_{6} \mathrm{O}_{2}\right)$ : calcd 611.5007; found 611.4948.

8d: 产率 $80 \% .{ }^{1} \mathrm{H}$ NMR (DMSO- $\left.d_{6}, 400 \mathrm{MHz}\right) \delta: 0.84$ $\left(\mathrm{t}, J=6.8 \mathrm{~Hz}, 3 \mathrm{H}, \mathrm{CH}_{3}\right), 1.19 \sim 1.23\left(\mathrm{~m}, 30 \mathrm{H}, \mathrm{CH}_{2}\right)$, $1.51 \sim 1.78\left(\mathrm{~m}, 6 \mathrm{H}, \mathrm{CH}_{2}\right), 2.25(\mathrm{t}, J=6.8 \mathrm{~Hz}, 2 \mathrm{H}$, $\left.\mathrm{OCOCH}_{2} \mathrm{CH}_{2}\right), 2.70 \sim 2.71\left(\mathrm{~m}, 4 \mathrm{H}, \mathrm{PhN}\left(\mathrm{CH}_{2}\right)_{2}\right), 2.86 \sim$ $2.88\left(\mathrm{~m}, 4 \mathrm{H}, \mathrm{N}\left(\mathrm{CH}_{2} \mathrm{CH}_{2}\right)_{2}\right), 3.09 \sim 3.13(\mathrm{~m}, 8 \mathrm{H}$,
$\left.\mathrm{N}\left(\mathrm{CH}_{2} \mathrm{CH}_{2}\right)_{2}\right), 3.71\left(\mathrm{~s}, 2 \mathrm{H}, \operatorname{ArC} \mathrm{H}_{2} \mathrm{~N}\left(\mathrm{CH}_{2} \mathrm{CH}_{2}\right)_{2}\right), 4.10$ (t, $\left.J=7.6 \mathrm{~Hz}, 2 \mathrm{H}, \mathrm{CH}_{2} \mathrm{OCO}\right), 4.17(\mathrm{t}, J=7.9 \mathrm{~Hz}, 2 \mathrm{H}$, $\left.\mathrm{NCH}_{2} \mathrm{CH}_{2}\right), 5.42\left(\mathrm{~s}, 2 \mathrm{H}, \operatorname{ArCH}{ }_{2} \mathrm{~N}(\mathrm{CH})(\mathrm{CH})\right), 7.37 \sim 7.42$ (m, 4H, $\mathrm{CH}_{2} \mathrm{ArCH}_{2}$ ), 7.80 (s, 1H, imidazole-H), 9.35 (s, $1 \mathrm{H}$, imidazole-H); ${ }^{13} \mathrm{C}$ NMR $\left(100 \mathrm{MHz}, \mathrm{DMSO}-d_{6}\right) \delta$ : $173.0,136.1,135.8,133.9,130.6,128.3,122.8,122.5$, $118.6,115.7,63.6,56.0,54.9,51.6,48.9,47.0,44.6,42.0$, $40.0,39.8,39.6,39.4,39.2,39.0,38.8,33.5,31.2,29.3$, 28.9, 28.9, 28.8, 28.7, 28.6, 28.3, 28.1, 24.5, 22.1, 13.9. HRMS $\mathrm{C}_{42} \mathrm{H}_{75} \mathrm{~N}_{6} \mathrm{O}_{2}$ calcd 695.5962; found 695.5897.

\section{3 阳离子脂质体的制备}

在室温下, 在一个灭菌的 $25 \mathrm{~mL}$ 圆底烧瓶中, 将 $0.0025 \mathrm{mmol}$ 阳离子脂质 $\mathbf{8}$ 与不同摩尔比例的 DOPE 混 合、溶解于无水氯仿中, 完全溶解后, 用旋转蒸发仪 (转速为 $60 \mathrm{r} / \mathrm{min}$ ) 室温下缓慢蒸除氯仿得到脂质体膜, 该脂质体膜经真空干燥(真空度 $0.095 \mathrm{MPa}$, 时间 $12 \mathrm{~h}$, 温度 $25{ }^{\circ} \mathrm{C}$ ) 去除残留氯仿得到干燥脂质体膜, 将干燥脂 质体膜和要使用的 Tris- $\mathrm{HCl}$ 缓冲溶液( $\mathrm{pH}$ 值 7.4, 浓度 $10 \mathrm{mmol} / \mathrm{L}$ ) 升温至 $70{ }^{\circ} \mathrm{C}$, 然后将 $2.5 \mathrm{~mL}$ Tris- $\mathrm{HCl}$ 缓冲 溶液加入到脂质膜反应瓶, 摇动或涡旋振动是反应瓶上 的脂质体膜脱落并溶解, 再在 $60{ }^{\circ} \mathrm{C}$ 水溶中超声 $20 \mathrm{~min}$ 就得到 $1 \mathrm{mmol} / \mathrm{L}$ 的脂质体溶液, 将此脂质体溶液放置 于 $4{ }^{\circ} \mathrm{C}$ 冰箱内保存备用.

\section{4 阳离子脂质体/DNA 复合物的制备}

将不同量的阳离子脂质体溶液 $(1 \mathrm{mmol} / \mathrm{L})$ 与固定量 (电泳时 $5 \mu \mathrm{g}$, 转染时 $2 \mu \mathrm{g}$ ) 的 DNA (电泳时用 pGL-3, 转

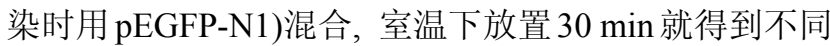
氮磷比 $(\mathrm{N} / \mathrm{P})$ 的阳离子脂质体/DNA 复合物. 这里的氮磷 比是指阳离子脂质上的氮原子的摩尔量与 DNA 上的磷 原子的摩尔量之比, DNA 的平均分子量为 350 .

\section{5 凝胶电泳实验}

按照不同的氮磷比, 取适当体积的上述脂质体溶液 $(1 \mathrm{mmol} / \mathrm{L})$, 用 $0.36 \mathrm{mmol} / \mathrm{L}$ 的葡萄糖溶液稀释至 $50 \mu \mathrm{L}$, 将此溶液滴加到含 $5 \mu \mathrm{g}$ pEGFP-N1 DNA 的 Tris-HCl (40 $\mathrm{mmol} / \mathrm{L}, \mathrm{pH}=7.4$ )缓冲液中, 混匀后于室温孵化 $30 \mathrm{~min}$ 得到不同氮磷比 $(0,2,4,6,8,10)$ 的脂质体/DNA 复合物. 将得到的脂质体/DNA 复合物用 $0.8 \%$ (质量分数)的琼脂 糖凝胶于 $110 \mathrm{~V}$ 下电泳 $30 \mathrm{~min}, \mathrm{~EB}$ 染色, 采用 Olympia 公司的 GDS 凝胶成像系统观测电泳结果.

\section{6 荧光溴乙锭置换实验}

阳离子脂质体对结合了 DNA 的溴乙锭的荧光减弱 用 Fluoromax-4 型苂光分光光度计测定(激发波长为 497 $\mathrm{nm}$, 激发波长和发射波长的狭缝都为 $3 \mathrm{~nm}$ ). 首先测定 $5 \mu \mathrm{mol} / \mathrm{L}$ 溴乙啶缓冲溶液 $(10 \mathrm{mmol} / \mathrm{L}$ Tris- $\mathrm{HCl}, \mathrm{pH} 7.4)$ 在发射波长 $605 \mathrm{~nm}$ 处的荧光强度 $\left(F_{0}\right)$, 然后在该溶液中 加入 CT-DNA 溶液保证 CT-DNA 在该溶液中的浓度为 大约 $11 \mu \mathrm{mol} / \mathrm{L}$, 搅拌两分钟使溴乙啶完全插入 
CT-DNA 形成复合物后, 再次测定该溶液在 $605 \mathrm{~nm}$ 处 的苂光强度 $\left(F_{\max }\right)$. 接着逐次向该溶液中加入阳离子脂 质体溶液, 使每次加入的脂质体浓度为 $0.68 \mu \mathrm{mol} / \mathrm{L}$, 每 次加完后摚拌两分钟后都测定记录该混合溶液在 605 $\mathrm{nm}$ 处的荧光强度 $\left(F_{\mathrm{x}}\right)$. 苂光减弱百分比按 $F I \%=\left(F_{\mathrm{x}}-\right.$ $\left.F_{0}\right) /\left(F_{\text {max }}-F_{0}\right) \times 100$ 计算.

\section{7 粒径和电位的测定}

阳离子脂质体和不同氮磷比的阳离子脂质体/DNA 复合物的粒径和电位同样用马氏粒径仪(Zetasizer Nano ZS, Malvern Instruments Led)测定. 首先按照不同的 N/P 量取所需阳离子脂质体与 DNA 的体积, 再用 $0.1 \mathrm{~mol} / \mathrm{L}$ 的 PBS 溶液稀释至 $1 \mathrm{~mL}$, 然后在室温 $25{ }^{\circ} \mathrm{C}$ 下测定记录 它们的粒径和电位.

\section{8 细胞培养}

A549 细胞(人肺癌细胞), 在含有 $10 \%$ 的小牛血清和 $1 \%$ 的抗生素(青霉素-链霉素, $10000 \mathrm{U} / \mathrm{mL}$ )的 RPMI 1640 培养基中培养. 培养时所有细胞都放在 $37{ }^{\circ} \mathrm{C}, 5 \%$ 的二氧化碳条件下培养.

\section{9 体外转染实验}

在进行转染前 $24 \mathrm{~h}$, 在 24 孔板上种植细胞, 保证在 转染时细胞长到 $80 \%$ \% $90 \%$ 的细胞密度. 对于转染时复 合物的制备, 首先将不同量的脂质体和 DNA 分别用无 血清和无抗体的 RPMI1640 或 DMEM 培养基稀释控制 总体积为 $200 \mu \mathrm{L}$, 然后将 DNA 溶液缓慢滴加到脂质体 溶液中, 室温下放置 $30 \mathrm{~min}$ 后即得到用于转染的阳离子 脂质体/DNA 复合物.

将细胞培养液中的培养基小心吸掉, 用无血清的 RPMI1640 或 DMEM 洗一次后, 将上述制备好放置了 30 $\min$ 的复合物加入相应的细胞孔中, 在 $37{ }^{\circ} \mathrm{C}, 5 \%$ 的二 氧化碳氛围下培养 $4 \mathrm{~h}$ 后, 吸掉培养基并加入 $500 \mu \mathrm{L}$ 含 有 10\%血清的 RPMI1640 或 DMEM 培养基. 继续在 37 ${ }^{\circ} \mathrm{C}, 5 \%$ 的二氧化碳氛围下培养 $24 \mathrm{~h}$ 后进行下一步的基 因表达情况测定.
对于荧光蛋白表达实验，转染时使用 pEGFP-N1 做 报告基因，按上述方法转染 $24 \mathrm{~h}$ 后在倒置苂光显微镜下 观察苂光表达情况并拍照.

\section{致谢}

感谢四川大学分析测试中心在样品测试方面给予 的帮助.

\section{References}

[1] Zhang, X.-Q. Nature 2003, 25, 153.

[2] Mintzer, M. A.; Simanek, E. E. Chem. Rev. 2009, 109, 259.

[3] Pennisi, E. Science 1998, 280, 814.

[4] Miller, A. D. Angew. Chem. Int. Ed. 1998, 37, 1768.

[5] Verma, I. M.; Somia, N. Nature 1997, 389, 239.

[6] Sheng, R.; Luo, T.; Zhu, Y.; Li, H.; Sun, J.; Chen, S.; Sun, W.; Cao, A. Biomaterials 2011, 32, 3507.

[7] Mikhail, A. M.; Tatyana, O. K.; Ivan, A. P.; Nina, G. M.; Galina, A. S.; Valentine, V. V.; Marina, A. Z. J. Controlled Release 2012, 160, 182.

[8] Shrinivas, V.; Yang, Y. Y. Biomaterials 2011, 32, 2369.

[9] Dai, J.; Zou, S.; Pei, Y.; Cheng, D.; Ai, H.; Shuai, X. Biomaterials 2011, 32, 1694

[10] Felgner, P. L.; Gadek, T. R.; Holm, M.; Roman, R.; Chan, H. W.; Wenz, M.; Northrop, J. P.; Ringold, G. M.; Danielsen, M. Proc. Natl. Acad. Sci. U. S. A. 1987, 84, 7413.

[11] Xiang, Y.-Z.; Liao, Y.-L.; Zhang, J.; Zhang, D.-W.; Chen, S.-H.; Lu, Q.-S.; Zhang, Y.; Lin, H.-H.; Yu, X.-Q. Bioorg. Med. Chem. Lett. 2009, 19, 3458 .

[12] Li, S.; Wang, Y.; Zhang, J.; Yang, W.-H.; Dai, Z.-H.; Zhu, W.; Yu, X.-Q. Mol. Biosyst. 2011, 7, 1254.

[13] Yi, W.-J.; Feng, Z.-H.; Zhang, Q.-F.; Zhang, J.; Li, L.-D.; Zhu, W.; Yu, X.-Q. Org. Biomol. Chem. 2011, 9, 2413.

[14] Huang, Q.-D.; Ren, J.; Ou, W.-J.; Fu, Y.; Cai, M.-Q.; Zhang, J.; Zhu, W.; Yu, X.-Q. Chem. Biol. Drug Des. 2012, 79, 879.

[15] Huang, Q.-D.; Zhong, G.-X.; Zhang, Y.; Ren, J.; Fu, Y.; Zhang, J.; Zhu, W.; Yu, X.-Q. PLoS One 2011, 6, e23134

[16] Huang, Q.-D.; Ou, W.-J.; Chen, H.; Feng, Z.-H.; Wang, J.-Y.; Zhang, J.; Zhu, W.; Yu, X.-Q. Eur. J. Pharm. Biopharm. 2011, 78, 326.

[17] Savva, M.; Chen, P.; Aljaberi, A.; Selvi, B.; Spelios, M. Bioconjugate Chem. 2005, 16, 1411.

[18] Koiwai, K.; Tokuhisa, K.; Karinaga, R.; Kudo, Y.; Kusuki, S.; Takeda, Y.; Sakurai, K. Bioconjugate Chem. 2005, 16, 1349.

[19] Huang, Q.-D. Ph.D. Dissertation, Sichuan University, Chengdu, 2011. (黄清东, 博士论文, 四川大学, 成都, 2011.) 